\title{
Conditionalized Imperatives
}

\author{
Magdalena Schwager \\ Johann Wolfgang Goethe-Universtität Frankfurt
}

\section{Imperatives as Clause-Types}

Before talking about conditionalized imperatives, I want to ensure a common understanding of 'imperative', namely as a clause type in the sense of Sadock and Zwicky (1985). That means that for a given language $\mathscr{L}$, imperative will be taken to denote one of $\mathscr{L}$ 's form types at sentence level, namely the one tokens of which are prototypically used for ORDERs or COMMANDs. As such they are paralleled by declaratives (used for ASSERTIONs), interrogatives (for informationseeking QUESTIONs) and for some languages also exclamatives and perhaps more.

A natural choice for explaining this clause type system is to assume that it is encoded semantically, in the sense that the semantic object assigned to a particular sentence form determines its prototypical usage. The actual speech act performed by uttering a token of that type is then determined by the interaction of the semantic object expressed with the context of utterance. Imperatives are well-known to pose problems for a semantic treatment because they lack a straightforward link to the anchors of both static and dynamic semantics, namely the concepts of truth/falsity and of information growth. In that, they differ from interrogatives that have been linked quite successfully to both via the concept of answerhood. On the other hand, the speech act types associated with imperatives vary too widely in order to associate them in a straightforward way with a speech act (understood as a semantic element) or a particular type of update (as it can be proposed in a dynamic framework, cf. e.g. Zarnic 2002, Mastop 2005).

This unclear and most likely non-propositional status is of course most problematic when it comes to (compositional) integration of imperatives into larger compounds, something which is very rare indeed. For example, very few languages allow for imperatives to occur in indirect speech (cf. Schwager $2005 \mathrm{~b}$ for discussion). One of the very few complex sentence types in which (cross-linguistically) imperatives occur quite naturally are conditionals:

a. If you see something, say something!

b. Whenever you want a beer, check the fridge first!

A previous version of the paper has been presented at the 7th Szklarska Poręba workshop the audience and organizers of which I want to thank. For helpful discussion and comments I am grateful in particular to Ede Zimmermann and Adrian Brasoveanu; I also want to thank Nicholas Asher, Tim Fernando, Michael Franke, James Higginbotham, Utpal Lahiri, Rick Nouwen, Hong Zhou, and three anonymous reviewers. For help with the English data, I am indebted to Peter Sells, Tony Veale, and Carl Vogel. Of course, the usual disclaimer applies. 
I call these conditionalized imperatives (CIs), and will in the following try to shed some light on how the imperative and the conditionalization are to interact.

CIs would of course be unproblematic for any theory of imperatives if they were confined to conditionals that encode a relation between consequent and antecedent at speech act level (in the sense of relevance or factual conditionals). Therefore, I will first show that CIs occur as truly hypothetical conditionals as well. Next, I will argue that an analysis in terms of hypothetical speech acts (HSA) does not seem to capture all there is about CIs. I then proceed to propose a modal operator analysis (MOP) for imperatives which assimilates imperatives to performative usages of modal verbs. ${ }^{1}$ It will be shown that MOP accounts naturally for the various subtypes of the (problematic) class of hypothetical imperatives (interaction with quantificational adverbials, epistemic and non-epistemic conditionals) and the absence of counterfactual CIs.

\section{The Conditional Landscape}

Iatridou (1991) distinguishes three major classes of conditionals: relevance, factual and hypothetical conditionals. I will first show that CIs can be found within all three of them. In the remainder of the paper I will then focus exclusively on hypothetical conditionals.

\subsection{Relevance Conditionals}

Relevance conditionals ${ }^{2}$ do not express that there is a relation in terms of truth or probabilities between antecedent and consequent. Rather, the antecedent filters out one of the conditions (typically relevance) under which the speech act arising from an utterance of the consequent in the given context would be appropriate. This reading is lost if we insert then or only (or in general, if prosodic integration is forced):

(2) a. If you are thirsty, ( ${ }^{\#}$ then) there is beer in the fridge.

b. ${ }^{\#}$ Only if you are thirsty, there is beer in the fridge.

Some CIs are clearly relevance conditionals. Consider (3a), which loses its most natural reading if modified by then or only (under prosodic integration).

(3) a. If I may be honest, better call Andreas as soon as possible.

b. " If I may be honest, then better call Andreas as soon as possible.

c. \#Only if I may be honest, call Andreas as soon as possible.

This is not surprising; imperatives can of course be used to perform speech acts, and thus come with appropriateness conditions that can need filtering.

\footnotetext{
${ }^{1}$ The analysis has been developed and motivated independently from CIs in Schwager (2005b).

${ }^{2}$ They are sometimes also called biscuit conditionals or speech act conditionals.
} 


\subsection{Factual (or Premise) Conditionals}

Again, the relation between antecedent and consequent is not one in terms of truth or probability. Here, the antecedent is presupposed to be true (or presupposed to be believed by the addressee) and specifies the motivation for performing the speech act corresponding to the consequent. In these cases, then is acceptable, but modification with only is disallowed.

(4) a. If you like him so much, why don't you help him then?

b. ${ }^{*}$ Only if you like him so much, why don't you help him (then)?

Again, it is not surprising that, alongside interrogatives, imperatives occur as consequents of factual conditionals:

a. If you like him so much, then go ahead and help him!

b. ${ }^{*}$ Only if you like him so much, then go ahead and help him!

\subsection{Hypothetical Conditionals}

The only class of conditionals whose manifestation as CIs might be surprising are hypothetical conditionals. These are usually taken to express that the truth (or the probability) of the consequent depends on the truth (or the probability) of the antecedent. The antecedent (at least with indicative conditionals) is presented as something the truth of which is not known to the speaker.

In (2) and (4) we have seen that hypotheticality is enforced by inserting then or only. Moreover, only hypothetical conditionals allow for binding from the consequent into the antecedent:

a. If you really like $i_{i}$, a donkey ${ }_{j}$ will be grateful.

$o k_{\mathrm{i}}=\mathrm{j}$

b. If I may tell you something about its health ${ }_{i}$, let a donkey ${ }_{j}$ rest every now and then.

$\# \mathrm{i}=\mathrm{j}$

c. If you have $\mathrm{it}_{i}$, why don't you keep a donkey ${ }_{j}$ in your garden? $\quad \#_{\mathrm{i}}=\mathrm{j}$

The examples in (7) allow for binding and prosodic integration, which warrants that CIs can constitute hypothetical conditionals.

a. If $\mathrm{it}_{i}$ is tired, let a donkey ${ }_{j}$ rest.

b. Call a doctor only if you are sick.

Hypothetical CIs are the only class that is truly interesting for the semantics of imperatives, in that the correlation between antecedent and consequent seems to exist at sub-speech act level and hence forces us to ask how if-clause and imperative are to interact. Propositional as well as non-propositional analyses rely on the fact that both parts are propositional. For propositional analyses (in terms of material implication, strict implication or variably strict implication) this is quite obvious, but also probabilistic accounts relate probabilities of antecedent and consequent propositions (cf. Ramsey 1929, recently Kaufmann 2005). We may therefore conclude that standard treatments do not automatically carry over to CIs. 


\section{Hypothetical Speech Act Analysis}

A common way to think of hypothetical CIs is to treat them as imperatives depending on whether a certain condition holds (Segerberg 1990, Zarnic 2002, Asher and Lascarides 2003, Mastop 2005). I have lumped such approaches together under the label of hypothetical speech act analysis (HSA). ${ }^{3}$ Taking ! to turn a proposition $\psi$ of the form you do $P$ into whatever semantic object corresponds to an imperative, we can represent HSA schematically as in (8):

$$
\phi \longmapsto ! \psi .
$$

According to (8), the effect corresponding to the imperative only has an impact at a point of evaluation where the antecedent is true (or constitutes a successful update). Depending on the interpretation of $\succ$, we can distinguish between analyses that leave the information state unchanged in case the antecedent is not true at the point of evaluation (cf. Segerberg 1990; Zarnic 2002's first version) and those that amount to a disjunctive update if the information state does not decide the antecedent (keeping both worlds where $\phi$ is true and $\psi$ is commanded and worlds where $\phi$ is not true and both $\psi$ and $\neg \psi$ remain permitted; cf. Zarnic 2002). ${ }^{4}$

What all of these analyses have in common is that they treat the imperative effect as dependent on the antecedent, consequently, the complex sentence is not an imperative. On the one hand, this is in contrast to the insight gained in syntax that the clause type of hypothetical conditionals is determined by the clause type of the matrix clause (cf. Bhatt and Pancheva 2006). On the other hand, even if ultimately the predictions depend on how $\succ$ and! are understood precisely, the following phenomena appear problematic for HSA. So far, they have not been addressed explicitly within HSA, and as far as I can tell, they suggest different scopal relations or simply a tighter interaction between antecedent and consequent.

Intuitively, hypothetical conditionals themselves are a pretty inhomogenous class, consider the paradigm in (9). Both (9a) and (9b) are naturally understood to talk about a particular situation, (9c) talks about all relevant situations.

a. If it starts raining, take the bus.

b. If it is raining, take the bus.

c. If it rains, always take the bus.

The various versions of HSA proposed so far (implicitly) focus on cases like (9b). Covering all cases is not straight-forward. At least for quantificational adverbials like (9c), it is easy to see that a naive extension of HSA makes unwanted predictions

\footnotetext{
${ }^{3}$ This should not mean that they assume that depending on the antecedent, a speech act is fulfilled or not, in the sense that e.g. falsifying the antecedent would exempt the speaker from having made any (relevant) action. The theories I have been looking at in more detail are all concerned with a hypothetical imperative effect, independently of what speach act is to be assigned to the complex sentence.

${ }^{4}$ Asher and Lascarides (2003) achieve a similar effect: $\neg \phi$-worlds are kept, $\phi$ worlds are changed to $\psi$-worlds, leaving us with an information state that verifies $\neg \phi \vee \psi$. Cf. Schwager (2005b) for a critique of the unconstrained change to $\psi$-worlds and the ultimately purely epistemic impact.
} 
with respect to the scopal interactions. This becomes visible with quantificational adverbials such as never. ${ }^{5}$ The preferred reading for (10a) makes it come out similar to (10b): the imperative has to take scope over the negation and expresses a rule holding in general, not just for a particular occasion; consequently, what we want is something along the lines of (11a). HSA allows us to predict (11b) or maybe (11c) - the former is a possible reading different from $(10 \mathrm{~b}),(11 \mathrm{c})$ is unavailable. ${ }^{6}$

(10) a. If your boss comes in never stare at him!

b. Whenever your boss comes in don't stare at him!

a. ! $\neg(\exists t)[$ your boss comes in at $t][$ you stare at him at $t]$

b. your boss comes in at $t \longmapsto ! \neg\left(\exists t^{\prime}\right)\left[t^{\prime} \subseteq t\right]\left[\right.$ you stare at him at $\left.t^{\prime}\right]$

c. ${ }^{*} \neg(\exists t)$ [your boss comes in at $t \&$ ! (you stare at him at $\left.t\right)$ ]

HSA fails to predict the correct interaction with adverbially quantified CIs.

Furthermore, consider Hare (1971)'s contrast between anankastic and other conditionals as given in (12).

a. If you want sugar in your coffee, you should call the waiter!

b. If you want sugar in your soup, you should get tested for diabetes!

While (12a) expresses that calling the waiter is a means to achieve your goal, (12b) expresses that the addressee's wish is a symptom for a certain necessity. CIs replicate the contrast:

(13) a. If you want sugar in your coffee, call the waiter!

b. If you want sugar in your soup, get tested for diabetes!

Again, I doubt that a uniform treatment in terms of (8) can capture the difference between the two dependencies.

Moreover, CIs replicate a difference in the possibility of binding from the consequent into the antecedent that has been observed to distinguish different classes of hypothetical conditionals. In Section 5, the contrast in (3) will be treated as evidence in favour of a distinction between epistemic and non-epistemic instances of CIs.

\footnotetext{
${ }^{5}$ The argument only holds for approaches that focus on the non-epistemic nature of the imperative (cf. Zarnic 2002, Portner 2005, Mastop 2005). Asher and Lascarides (2003)'s analysis does not run into the problem since it forces the information state into one where all worlds are such that at no moment the boss comes in you stare at him, which is indeed what we want. I am indebted to one of my reviewers for pointing this out.

${ }^{6} \mathrm{We}$ might consider turning (11b) into the right reading by adding a covert always. I am indebted to Ede Zimmermann for drawing my attention to non-distributive predicates that clearly show that this is not the right way to go.

(i) a. If your boss comes in, never wink less than three times.

b. always $t_{t}$ [y. b. comes in at $\left.t\right] !\left[\neg\left(\exists t^{\prime}\right)\left[t^{\prime} \subseteq t\right]\left[\right.\right.$ there are less than 3 winking events in $\left.\left.t^{\prime}\right]\right]$

Intuitively, (ia) is satisfiable, but (ib) is not: for no interval of more than three winking events is it the case that every subinterval also contains three winking events.
} 
(14) a. If you want him $_{i}$ to say nice things about your work, treat every professor $_{i}$ with courtesy.

b. ${ }^{*}$ If he ${ }_{i}$ is already there, give every speaker $_{i}$ his badge.

For ordinary conditionals, most of the contrasts mentioned above have been analyzed as dependent on the modality present in the matrix clause of the conditional. In the next section, I will propose an analysis for imperatives that assimilates them to modal verbs and thus allows for a construal of CIs alternative to HSA.

\section{Imperatives, Modal Operators, and Conditionals}

\subsection{Imperatives as Modal Operators (MOP)}

\subsubsection{Descriptive and Performative Modal Verbs}

Imperatives prove problematic for semantics for two reasons: they lack an obvious connection to truth values (cf. 15), yet at the same time, their effects are too manifold to associate them directly with a particular speech act (e.g. by letting them constrain the set of deontically accessible worlds), cf. (16):

A: Close the door!

B: "That's true.

a. Get well soon!

WISH

b. Take a cookie if you want.

PERMISSION

c. Close that door immediately!

ORDER

d. From Shibuya, take the Inokashira line to Komaba Todaimae. AdVICE

I want to suggest comparison with modal verbs as a natural starting point. They allow for descriptive usages, on which they describe the way the world is with respect to certain obligations, needs, etc. (e.g. 17b). On the other hand, we find modal verbs in context where they seem to themselves bring about the corresponding modal facts (called performative usages; e.g. 17a).

a. You may pay for this. (supervisor to student in the cafeteria)

b. You may use a credit card. (They accept all major types.)

I follow Kamp (1978) and Schulz (2003) in assuming that descriptive and performative modal verbs share the same (propositional) semantics. The difference will be argued to fall out from a particular setting of contextual parameters.

Now, I want to argue that imperatives are like performative usages of modal verbs; that is, the same semantic object underlies (18a) and (18b).

a. You must close the door immediately!

b. Close the door immediately! 
I assume that imperatives contain a modal operator semantically like must which comes with presuppositions that constrain it to contexts in which a modal verb like must would be used performatively.

For the semantics of the modal operator, I follow the standard possible worlds semantics as laid out in Kratzer (1991). ${ }^{7}$ Modal verbs express necessity or possibility of a proposition with respect to two parameters, namely a modal base $f$ and an ordering source $g$. Both are functions from worlds into sets of propositions (conversational backgrounds). ${ }^{8}$ The former assigns each world $w$ a set of worlds to be taken into consideration, and the latter assigns each world $w$ a set of propositions that are used to induce an ordering relation on a set of possible worlds.

$$
\begin{aligned}
& \text { preorder } \leq_{g(w)}: \\
& v \leq_{g(w)} z \text { iff }\{p \in g(w) \mid z \in p\} \subseteq\{p \in g(w) \mid v \in p\}
\end{aligned}
$$

We can now define the set of worlds in the background given by $f$ that are optimal according to the ordering source $g$ at $w{ }^{9}$

$$
O(f, g, w)=\left\{v \in \cap f(w) \mid \forall z \in \cap f(w): \text { if } z \leq_{g(w)} v \text { then } v \leq_{g(w)} z\right\}
$$

The semantics of the modal verbs must and may can now be given as in (21). ${ }^{10}$

$$
\begin{aligned}
& \text { a. [[ must }]^{c, s}=\lambda f \lambda g \lambda p \lambda w .\left(\forall w^{\prime} \in O(f, g, w)\right)\left[p\left(w^{\prime}\right)\right] \\
& \text { b. }[[\text { may }]]^{c, s}=\lambda f \lambda g \lambda p \lambda w .\left(\exists w^{\prime} \in O(f, g, w)\right)\left[p\left(w^{\prime}\right)\right]
\end{aligned}
$$

The various 'readings' for modal verbs (e.g. epistemic, deontic, buletic, ...) depend on the particular interpretation of modal base and ordering source. Now, the performative effect arises only if the parameters involved are such that the speaker is known to have perfect knowledge about them. Consequently, she utters a necessity proposition she cannot be mistaken about. Moreover, the ordering source has to be constituted by some sort of preferences. Then, roughly, if nothing speaks against her utterance constituting a speech act that makes the necessity (or possibility) proposition expressed true (e.g. that she is giving a COMMAND - to be defined as rendering something obligatory which was not obligatory before), her utterance is taken as a performance of that speech act.

\subsubsection{Integrating Imperatives}

If we set aside for a moment permission imperatives, we can generalize the contribution of an imperative to saying that among all the ways the speech situation

\footnotetext{
${ }^{7}$ Based on Lewis (1973) and Kratzer (1978); cf. van Fraassen (1973) for similar ideas.

${ }^{8}$ I slightly deviate from the original account in that modal base and ordering source are represented by free variables in the object language ('pronouns', interpreted via assignment $s$ ). They constitute arguments of the modal operator (cf. von Stechow 2004, von Fintel and Iatridou 2005).

${ }^{9}$ The formula is simplified relying on Lewis (1973)'s Limit Assumption, which ensures that there is a well-defined set of optimal worlds.

${ }^{10}$ Interpretation proceeds via a standard interpretation function $[[\cdot]]^{c, s}$, which assigns each expression its meaning at a context $c$ (specifying a triple of speaker $c_{S}$, utterance time $c_{T}$, and utterance world $\left.c_{W}\right)$ w.r.t. an assignment $s$.
} 
could evolve those are best (according to some contextually given ideal) that make the complement proposition true. This accounts naturally for WISHES that order with respect to what the speaker wants, COMMANDS (w.r.t. what the speaker commands), ADVICE (w.r.t. the hearer's preferences), etc.

To spell it out, I assume that imperatives contain a modal operator $O P_{I m p}$, which is interpreted as a slightly more restricted version of must. Normally, it expresses necessity with respect to the Common Ground as the modal base (consequently, the modal base is fixed lexically and $f$ is the empty conversational background $e$ (for any world $w, e(w)=\emptyset$ ). $f$ adduces additional information only in the case of ADVICE. ${ }^{11}$ Furthermore, we need a contextually given set of preferences as an ordering source $g$. (I use $c g^{c}$ for the function that maps any world to the set of propositions that are mutual joint belief in $c$ and thus describe the Common Ground in $c$; $\mathbb{U}$ is pointwise union of two conversational backgrounds. $)^{12}$

$$
\llbracket O P_{\text {Imp }} \rrbracket^{c, s}=\lambda f \lambda g \lambda p \lambda w \cdot\left(\forall w^{\prime} \in O\left(c g^{c} \cup f, g, w\right)\right)\left[p\left(w^{\prime}\right)\right]
$$

According to (22) an imperative $\phi$ ! could in principle express any proposition that $\phi$ is necessary in those worlds held possible by speaker and addressee that come closest to some contextually given ideal. In order to constrain this to the usages we actually find, we postulate an additional presuppositional meaning component. Descriptive usages are excluded by the following three requirements that constrain the interpretation of the free variables $f$ and $g$ :

First, we require that the speaker is an authority on all parameters involved. This is spelt out in terms of exhaustive knowledge à la Groenendijk and Stokhof (1984) (cf. Zimmermann 2000; Bel $_{c_{S}}(w)$ is the set of worlds compatible with what the speaker believes in $w$.)

(23) The speaker $c_{S}$ is an authority on a conversational background $f$ in $c$ iff

$$
\begin{gathered}
f \in A U T H\left(c_{S}\right)(c), \text { where } \operatorname{AUTH}\left(c_{S}\right)(c)=\{f: W \rightarrow \operatorname{POW}(\operatorname{POW}(W)) \mid \\
\left.\left(\forall w \in C G^{c}\right)(\forall p)\left[p \in f(w) \leftrightarrow\left(\forall w^{\prime} \in \operatorname{Bel}_{c_{S}}(w)\right)\left[p \in f\left(w^{\prime}\right)\right]\right]\right\} .
\end{gathered}
$$

Of course, $c g^{c}$ is in $A U T H\left(c_{S}\right)(c)$ for any context $c$ (the empty conversational background $e$ likewise), so we only need to require that $g$ and an eventual non-empty $f$ (for ADVICE) are in $\operatorname{AUTH}\left(c_{S}\right)(c)$.

\footnotetext{
${ }^{11}$ Consider a scenario as in (i):
}

(i) A: How do I get to Shibuya?

B: Take the Inokashira Line.

This might have a reading where indeed both speaker and hearer have perfect knowledge about (the relevant part of) transportation in Tokyo, and the information given consists only in what kind of preferences to apply (e.g. if saving money or saving time is more important). But it is a lot more natural in a scenario where speaker and hearer agree on what the common preferences are, and the speaker is thus giving information as to what option meets them best. Consequently, she is bringing in additional facts that restrict $C G^{c}$. Again, in order for the imperative to be acceptable, the speaker has to be an authority over these facts.

${ }^{12}$ For each $c, c g^{c}$ is that function from $W$ to $P O W(P O W(W))$, s.t. for all $w$ in $C G^{c}: \cap c g^{c}(w)=$ $C G^{c}$.

For all $f, f^{\prime}$, functions $W \rightarrow P O W(P O W(W))$, and $w \in W:\left(f \cup f^{\prime}\right)(w) \leftrightarrow\left(f(w) \cup f^{\prime}(w)\right)$. 
Second, we require that the ordering source is preference related, in order to rule out ordering sources like what the speaker takes to be most plausible, etc.

Third, the speaker has to affirm the ordering source in $c$ as a good maxim for acting in the given scenario. ${ }^{13}$

The proposition expressed by an imperative $\phi$ ! thus amounts to saying that the worlds in $C G$ that are best according to some contextually given preference are $\phi$-worlds, where the speaker has perfect knowledge of these preferences and considers them a good guideline for acting in the given scenario.

As it stands, the theory does not explain PERMISSION-readings (cf. 16b). Giving a permission with an imperative requires overt modification (modal particles, reduced if you like-antecedents). Consequently, I think an analysis should treat them as somehow marked. In Schwager (2005c) I have proposed to derive them indirectly via pragmatic reasoning from According to your wish to do $\phi$ and not do anything I don't allow you, it's best that you do $\phi .{ }^{14}$

\subsection{Conditionals}

Conditionals can now be analyzed by letting if-clauses constrain the modal base of a modal operator to those worlds that make the antecedent true (cf. Lewis 1973, Kratzer 1978). They are thus analyzed as in (24).

$$
\begin{aligned}
& \text { [I [ If } \left.\left.\phi,[\mathrm{MOP} \mathrm{fg}] \psi]]^{c, s}=\llbracket\left[\mathrm{MOP} \mathrm{f}^{+} \mathrm{g}\right] \psi\right]\right]^{c, s}, \\
& \text { where } f^{+}=\lambda w \cdot f(w) \cup\left\{\llbracket \phi \rrbracket^{c, s}\right\} .
\end{aligned}
$$

Conditionals that lack an overt modal operator are assumed to host a covert must of epistemic necessity.

\footnotetext{
${ }^{13}$ It is not clear to me, how this requirement can be made precise. It is needed to account for the deontic variant of Moore's paradox (cf. Frank 1996). Take $g=$ the preferences of my tourist guide. Without the requirement of speaker affirmation, (ia) should be just as good as (ib).

(i) a. (According to my tourist guide) Go to Kyoto! "But I don't think you should do it.

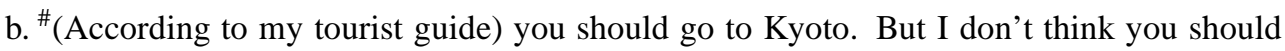
really do it.

In (ib) should has a preference for the speaker centered (and thus affirmed ordering source) underlying the second sentence as well, thus causing a contradiction. But this can be overcome by explicitly adding the different conversational background as constituted by the tourist guide. In contrast to that, the restriction to a speaker affirmed ordering source cannot be overridden for the imperative. Note, that the ordering source itself need not correspond to the speaker's preferences: In some cases, the interests lie clearly on the side of the hearer, as in advices, cf. (ii). The common core is thus that the speaker thinks that the preferences under consideration are a justified maxim for acting.

(ii) If you want to go to Harlem, take the A train. (It meets all your requirements of not spending too much, not losing too much time, etc. "Yet I don't think that these are the right criteria.)

${ }^{14}$ Alternatively, one could assimilate PERMISSION-imperatives to a certain case of ADVICEimperatives with for example. In Schwager (2005a), these have led me to argue that the necessity operator found in imperatives is complex and consists in exhaustified possibility (cf. Schwager 2005a), a complication otherwise irrelevant for the present task.
} 
The semantics for imperatives developed in Section 4.1.2 allows for a treatment of CIs fully parallel to that of conditionals with modal verbs. $O P_{I m p}$ is the modal operator in (25b), just as must is in (25a).

a. If you see Jessica at the conference dinner, you must say hi.

b. If you see Jessica at the conference dinner, say hi!

Accordingly, CIs come out as complex imperatives. I call this particular analysis for CIs obtained from assuming that the imperative is a modal operator $\mathrm{MOP}_{C I}$. In (26), (25b) is interpreted to be true at a world $w$ if the addressee says hi at the preferred worlds in $C G^{c}$ where the addressee sees Jessica at the conference dinner.

$$
\begin{aligned}
& \mathbb{[}\left[\text { if [you see Jessica at the c.d.][ } O P_{\text {Imp }} \mathrm{f} \text { g [you say hi] ]] }\right]^{c, s}= \\
& \lambda w .\left(\forall w^{\prime} \in O\left(\operatorname{cg}^{c} \cup \lambda w .\{\text { you see Jessica at the c.d. }\}, g, w\right)\right) \\
& \text { [you say hi } \left.\left(w^{\prime}\right)\right]
\end{aligned}
$$

Hence, an utterance of (25b) in the given context constrains the Common Ground by leaving in only worlds where the speaker has the respective preferences (e.g. worlds $w$, s.t. $g(w)=\{$ whenever you meet a colleague I like under appropriate circumstances for greeting, you say hi\}. This rules out worlds in which Jessica is not a colleague I like or greeting is inappropriate at conference dinners.)

Turning CIs into complex imperatives differs crucially from all kinds of hypothetical speech act analyses. Consequently, it is time to take a look at the prediction it makes with respect to the potential problems individuated for HSA.

Assimilating imperatives to modals makes many analyses proposed recently for anankastic conditionals carry over immediately to CIs (e.g. Sæb $\varnothing 2002$, Huitink 2005). ${ }^{15}$ Quantificational adverbials can be integrated easily if we allow for the imperative operator to take widest scope and follow Lewis (1975) in letting the if clause restrict the quantificational adverbial. (10a) (repeated as 27a) is correctly predicted to come out as (10b).

a. If your boss comes in, never stare at him.

b. [[ $O P_{\text {Imp }} \mathrm{f} \mathrm{g}$ [never [if your boss comes in][you stare at him]] $]^{c, s}=$ $\lambda w .\left(\forall w^{\prime} \in O\left(c g^{c} \cup f, g, w\right)\right)\left[\neg(\exists t)\right.$ [your boss comes in at $t$ in $w^{\prime} \&$ you stare at him at $t$ in $\left.w^{\prime}\right]$,

where $g=$ what the speaker commands, $f$ empty

HSA and $\mathrm{MOP}_{C I}$ differ further in that the latter but not the former predicts that deliberately falsifying the antecedent should be a means of complying with a CI. An anonymous referee has suggested this as as evidence against $\mathrm{MOP}_{C I}$. I do not think that this is correct. For some examples it is completely natural to leave it to the addressee to either block the antecedent or satisfy the consequent, cf. (28). ${ }^{16}$

\footnotetext{
${ }^{15}$ The most recent analysis of von Fintel and Iatridou (2005) assumes a nested construal. If the nearness modality they are employing can be made compatible with my analysis, it requires the extension in Section 5. But one should pay attention to the fact that, in contrast to the nested cases considered so far, anankastic conditionals do not block binding relations; cf. e.g. (14a).

${ }^{16}$ Piwek (2001) expresses a similar view in a planning-based framework for imperatives. He argues that avoiding the antecedent is a strategy only if the consequent conflicts with further com-
} 
a. (I'd rather you wouldn't talk about it at all, but) if you tell Cecile about it, don't mention I was in Frankfurt last week.

b. If you get a bad mark, don't ever come back here!

c. Don't risk your life when driving. If you are tired, stop and have a nap.

The intuitive asymmetry between the two options of complying with a CI should perhaps be seen in light of the well-known tendency of antecedents to be topical.

\section{Nested Modality}

So far, we have assumed that an overt modal operator in the consequent would always act as the conditional operator. But Kratzer's framework acknowledges also an alternative construal under which the overt modality is treated as a fact in the world that depends on the antecedent. In that case, the role of the conditional operator is left to a covert element of epistemic necessity. von Fintel and Iatridou (2005) discuss the following example:

(29) a. If jaywalking is illegal in this town, that guy over there has to be punished.

b. $\square f_{\text {circ }}$ [jaywalking is illegal] $g_{c_{S}-\text { wishes }}$ [that guy over there is punished]

c. $\square f_{e p i}$ [jaywalking is illegal] [ $\square_{\text {law }}$ that guy over there is punished ]

The construal in (29b) is the one we have been considering so far. Here, has to, plays the role of the conditional operator, interpreted perhaps to be circumstantial. This reading is true of a scenario where the speaker does not know if jaywalking is illegal, but thinks it should not be. He is convinced that, if it was illegal, the guy he is pointing at (some hard-core lobbyist of the automobile industry) was responsible and thus deserved punishment. The construal in (29c) makes use of the alternative we have just introduced. Again the speaker does not know if jaywalking is illegal, but in case it is, this would mean that the law is such that it requires punishment for the guy he is pointing at and who is obviously jaywalking.

At this point we have to ask ourselves if CIs ever constitute cases of nested modality. That is, can we observe a difference between CIs that depend on overall preferences and CIs with antecedent-based preferences? At first glance, a nested reading might be unexpected, since imperatives cannot normally be embedded under modal operators. ${ }^{17}$ Nevertheless, I will show that some CIs appear to involve nested modality. The MOP-analysis for imperatives will extend naturally to these

mitments of the addressee. Thus switching from mere (dis-)obedience to reasons for action seems promising, also with respect to the discussion in Dummett (1964). I think that the addressee centered view should be replaced by one in terms of mutual joint belief though. This comes natural in my analysis for imperatives.

${ }^{17}$ Cases like German (i) might seem to contradict that.

(i) Ruf ihn vielleicht mal an.

call.IMP him maybe Q-PARTICLE up

'Maybe, you better call him.' 
cases once we allow to interpret imperatives with respect to a subset of the Common Ground that has been made salient in the context. But before we start investigating CIs, it might be useful to take a look at general evidence for nested construals.

\subsection{CIs and Epistemicity}

Covert modal operators giving rise to nested modality as in (29c) are generally assumed to encode epistemic necessity. Consequently, we obtain epistemic conditionals. These draw on an uncertainty as to what is the case (and thus could be known in principle), in contrast to metaphysical conditionals that draw on uncertainty as to how the world is to evolve (which cannot be known yet, at least under a non-deterministic view; cf. Kaufmann 2005). CIs occur naturally with both types of antecedents. The antecedent proposition can be decided (30a), or still open (30b).

(30) a. If the airport shuttle has already left, take the train.

b. If you miss the airport shuttle, take the train.

Moreover, elements of epistemic modality are generally known to impose limits on outscoping by other quantifiers (cf. von Fintel and Iatridou 2003) ${ }^{18}$ In particular, epistemic conditionals seem to disallow cataphoric binding into the if-clause (cf. Zhou 2005): (31a) expresses a general rule and allows for binding, whereas (31b) checks whether a particular constellation holds at utterance time. The latter is an instance of an epistemic conditional, and binding is unacceptable. In (32), the binding contrast is replicated for CIs.

a. If you say nice things about his $i$ work, you will find every professor $_{i}$ willing to talk to you.

b. * If he ${ }_{i}$ is already here, every senator ${ }_{i}$ will help you.

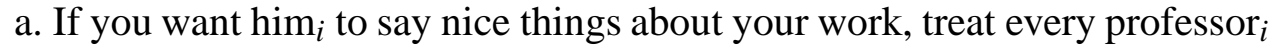
with courtesy.

b. If you find $\operatorname{him}_{i}$ interested in your work, ask every professor ${ }_{i}$ to write a letter of recommendation for you.

c. ${ }^{*}$ If he ${ }_{i}$ is already here, give every speaker ${ }_{i}$ his badge.

So it seems that we might expect the CI in (33) to allow for a reading analogous to the nested construal which was preferred for (29b). But this is not born out. (33) does not allow for the (in that case rather trivial) reading which says that in case jaywalking is illegal, according to the law, it is necessary that you do not jaywalk.

If jaywalking is illegal, don't do it.

Here we find an imperative modified with what usually functions as an adverb of epistemic possibility (vielleicht) used for very guarded advice. Nevertheless, I do not think that (i) involves an operator of epistemic possibility outscoping an imperative. Thurmair (1989)'s tests of stressing vielleicht or moving it into clause initial position suggest that it is a modal particle in such cases.

${ }^{18}$ But see data in Aloni (2001), also Tancredi (2005) for a caveat. 
But this is really a side-effect of the restrictions on the modality expressed by $O P_{I m p}$ (cf. Section 4.1.2). Even if (33) does not express that necessity with respect to the law depends on the antecedent, the preferred reading for (33) can only be obtained from a nested construal. Compare the two possibilities given in (34): ${ }^{19}$

$$
\begin{aligned}
& \text { a. } \lambda w \cdot\left(\forall w^{\prime} \in O\left(c g^{c} \cup \lambda w .\{\text { jaywalking is illegal }\}, g, w\right)\right) \\
& \text { [you don't jaywalk in } \left.w^{\prime}\right]
\end{aligned}
$$

A plausible scenario for (33) is the following: it is unknown to the addressee if the speaker wants her to obey the law; consequently, we find two types of worlds $\omega^{\prime}, \omega^{\prime \prime}$ in $C G^{c}$ that differ with respect to what the speaker wants $(=g): g\left(\omega^{\prime}\right)=\{$ you obey $\omega^{\prime}$ 's law $\}, g\left(\omega^{\prime \prime}\right)=\{\}$ (meaning, 'I don't care about the law'). In such a scenario, both construals (34a) and (34b) correctly rule out $\omega^{\prime \prime}$ worlds at which the speaker does not have the relevant preference. ${ }^{20}$ But in addition, (34a) rules out $\omega^{\prime}$-worlds at which jaywalking is not illegal: here, a preference for law-obedience does not come out as a preference against jaywalking, hence (34a) is false. So, (33) requires an analysis in terms of a nested construal.

Now, we have to check whether the alternative narrow scope construal obtained from MOP is needed as well. Intuitively, we have good evidence for that from paradigms like (30). And we can show that the nested construal makes wrong predictions for a particular type of CIs, namely second best imperatives:

Don't get lost! But if you do, call me.

A natural scenario for (35) is one where the ordering source $g$ is constituted by the preference of the speaker. Then, from the first imperative we learn that the speaker wants the addressee not to get lost (that is, $\left(\forall w \in C G^{c}\right)\left[\left(\lambda w^{\prime} . c_{A}\right.\right.$ doesn't get lost in $\left.\left.\left.w^{\prime}\right) \in g(w)\right]\right)$. $C G^{c}$ contains four types of worlds with respect to the future events of the addressee getting lost $(l)$ and calling (c), namely: $\omega_{1} \subseteq\{\neg l, c\}, \omega_{2}$ $\subseteq\{\neg l, \neg c\}, \omega_{3} \subseteq\{l, c\}, \omega_{4} \subseteq\{l, \neg c\}$. Each of these types is distinguished further according to the speaker's preferences. They differentiate the three possibilities

\footnotetext{
${ }^{19}$ It is highly controversial which kind of epistemic modality should be employed in indicative conditionals; I choose speaker-epistemic modality (instead of e.g. mutual joint belief, the CGmodality) so that they may convey information. This is sometimes challenged because sentences like (29c) are not felt to make claims about what the speaker believes, but rather about what the world is like. I do not consider this problematic, though. Even if encoded explicitly, speaker epistemic modality is often treated as 'invisible' in discourse:

(i) A: I believe it's raining.

B: "No, you don't./No, it's not.

${ }^{20}$ Note that in this scenario the speaker does not command perfect knowledge of what he wants: He knows that he has an overall preference for the hearer to obey the law, but he does not know what that exactly amounts to. Among the worlds doxastically accessible to him, we find both worlds where jaywalking is illegal and he has a preference for the hearer to avoid it and worlds where jaywalking is not illegal and he has no preference for the hearer to avoid it. The requirement of epistemic authority (cf. 23) has to be weakened to allow for such conditional insecurity over one's preferences.
} 
$g\left(\omega^{\prime}\right)=\{\neg l, \neg l \vee c\}, g\left(\omega^{\prime \prime}\right)=\{\neg l\}, g\left(\omega^{\prime \prime \prime}\right)=\{\neg l, c\}$. Again, the two construals come out as in (36).

a. $\lambda w .\left(\forall w^{\prime} \in O\left(c g^{c} \cup \lambda\right.\right.$ w. $\{$ you get lost $\left.\left.\}, g, w\right)\right)$ [you call me in $w^{\prime}$ ]

b. $\lambda w .\left(\forall w^{\prime} \in \operatorname{Bel}_{c_{S}}(w) \cap\right.$ you get lost $)\left[\left(\forall w^{\prime \prime} \in O\left(c g^{c}, g, w^{\prime}\right)\right)[\right.$ you call me in $\left.\left.w^{\prime \prime}\right]\right]$

This time, (36b) does not make the right predictions, though: the antecedent restricts attention to a subset of the $\omega_{3}$ - and $\omega_{4}$-worlds in CG (those compatible with the speaker's beliefs) and rules out all those worlds $w_{i}$ in CG that do not verify $O\left(\mathrm{cg}^{c}, g, w_{i}\right) \subseteq$ you call me. This eliminates $\omega_{3}$ - and $\omega_{4}$-worlds that are type $\omega^{\prime}$ or $\omega^{\prime \prime}$ with respect to preferences. So, $(36 b)$ would inform the hearer of an unconditional preference for calling. In contrast to that, (36a) predicts correctly that we end up with $C G^{c} \subseteq \lambda w \cdot[g(w) \subseteq\{\neg l, \neg l \vee c\}] .{ }^{21}$ Consequently, we have good reason to retain the $\mathrm{MOP}_{C I}$-construal made available by MOP.

At this point we might want to think a bit about the nature of the nested construals. If epistemic CIs result from embedding under an epistemic modal, it is highly surprising that imperatives cannot in general be embedded under modal operators of epistemic necessity. To resolve this puzzle, let's take a look at a different phenomenon, namely modal subordination. I will argue that imperatives like modal verbs - can to a certain extent be subject to modal subordination, and that the 'nested' reading of CIs is to be obtained in a similar fashion (its analysis thus coming close to certain types of HSA). Consider the German and English data in (37) and (38). ${ }^{22}$

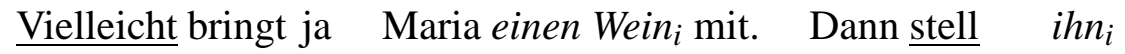
perhaps brings PRT Maria a wine along. then put.IMP it einstweilen in den Kühlschrank. in-the-meantime in the fridge

'Mary might bring some wine ${ }_{i}$ with her. In that case, put it ${ }_{i}$ in the fridge in the meantime.'

\footnotetext{
${ }^{21} \mathrm{~A}$ nested modality analysis could produce that effect by copying the restriction of the epistemic modal provided by the if-clause into the restrictor of the embedded modal, $O P_{I m p}$, as well. (E.g. along the lines of Frank 1996, who denies that non-epistemic modals can ever function as conditional operators.) I do not see much motivation for such a move though. We cannot really argue in terms of uniformity: the two construals are set apart by the copying mechanism, which in addition seems $a d$ hoc. Moreover, I do not think that the binding contrast (cf. 32) could be predicted from interaction with the copying mechanism.

${ }^{22}$ It might look suspicious that the presence of an anaphoric element (dann/in that case) is strongly preferred but this seems to constitute a general preference to be observed with non-epistemic modals (cf. i,ii). In contrast to that, epistemic modals do not require anaphoric elements (cf. iii).

(i) Mary might buy a lottery ticket ${ }_{i}$. Bill is such a careful guy, ${ }^{\#}$ he should keep $\mathrm{it}_{i}$.

(ii) Mary might buy a lottery ticket ${ }_{i}$. In that case, since Bill is such a careful guy, he should keep $\mathrm{it}_{i}$.

(iii) You should buy a lottery ticket ${ }_{i}$. You are such a lucky guy, $\mathrm{it}_{i}$ might be worth millions.
} 
(38) Ede might make lasagne ${ }_{i}$ tonight. ${ }^{? ? ?}{ }^{o k}$ (In that case) try it ${ }_{i}$, he's an excellent cook.

The proposal for CIs is thus to use $O P_{\text {Imp }}$ as the modal operator whenever the parameters with respect to which it is evaluated (the preferences) are independent of the antecedent. But for the other cases (that is, the epistemic ones), instead of a nested construal of modalities, I would like to propose that imperatives can sometimes get evaluated on a subset of the Common Ground. The subset in question might be determined by an if-clause or by a preceding clause expressing epistemic possibility (thus picking out a subset of $\mathrm{CG}$ ).

The remainder of the paper gives a rough sketch of imperatives as evaluated with respect to subsets of the Common Ground.

\subsection{Imperatives $\phi$ ! with Discourse Referents for Backgrounds}

So far, we have treated all conditionals as forming a single proposition. In order to capture the similarity to the modal subordination data, I will now assume that an alternative construal first introduces a set of worlds to be considered (a propositional discourse referent), and then evaluates the imperative with respect to that set of worlds. Crucially, the requirement that the imperative always takes the Common Ground as a background is loosened to the requirement that its background be a subset of the Common Ground.

To spell this out, I resort to DRT with propositional discourse referents and discourse referents for ordering sources along the lines of Geurts (1999). Here, modal operators are generally assumed to presuppose a background $b$ (an indexed proposition, which is a set of pairs $<$ world,assignment $>$ ), and an ordering source $g$ (as before, a world dependent set of propositions), and relate them to another propositional discourse referent. Now, the requirements spelt out in Section 4.1.2 are translated as restrictions on the presuppositional discourse referents $\underline{b}$ and $\underline{g} .{ }^{23}$ So, $b$ has to be a subset of the Common Ground ( $b \subseteq \mathrm{CG}$ ), $g$ has to be preferencerelated (pref-rel $(g))$ and affirmed by the speaker $\left(\operatorname{aff}\left(c_{S}, g\right)\right)$, and the speaker has to count as an authority on $g\left(\in A U T H\left(c_{S}\right)\right)$. The DRS built from an imperative (you) $P$ ! can now be given as in (39). The discourse referents for background $b$ and ordering source $g$ have to be anchored to suitable elements salient in the discourse, and a new referent $q$ is introduced for the worlds in the background at which the addressee satisfies the imperative.

$$
\left[\underline{\mathrm{b}}, \mathrm{q}, \underline{\mathrm{g}}: \mathrm{q}=\mathrm{b}+\left[: \mathrm{P}\left(c_{A}\right)\right], \mathrm{OPT}(\mathrm{b}, \mathrm{g}) \square q, \mathrm{~b} \subseteq \mathrm{CG}, \operatorname{pref}-\mathrm{rel}(\mathrm{g}), \mathrm{g} \in \operatorname{AUTH}\left(c_{S}\right)\right]
$$

At least after uttering the if-clause, a discourse referent $p$ that verifies the antecedent is salient and accessible. If it is a subset of the Common Ground, $b$ (the imperative's background) can be set to $p$. Necessity of the consequent is asserted only with

\footnotetext{
${ }^{23}$ I follow Geurts (1999) in underlining presuppositional discourse referents: they are either anchored to a previously introduced, accessible discourse referent or, if they possess enough descriptive content, can be accommodated.
} 
respect to the $g$-best worlds within $p$; these are called $\mathrm{OPT}(p, g)$ and are computed as follows: ${ }^{24}$

$$
\begin{aligned}
& \text { g-optimal worlds: } \llbracket \text { OPT }(\mathrm{p}, \mathrm{g}) \rrbracket\langle w, f\rangle= \\
& \left\{\left\langle w^{\prime}, g\right\rangle \in f(p) \mid \neg\left(\exists\left\langle w^{\prime \prime}, h\right\rangle \in f(p)\right)\left[w^{\prime \prime} \leq f(g)(w) w^{\prime} \& w^{\prime} \mathbb{E}_{f(g)(w)} w^{\prime \prime}\right]\right\}
\end{aligned}
$$

A nice, independent prediction is obtained if we assume that counterfactual conditionals arise from making salient a propositional discourse referent $p$ which is not a subset of $\mathrm{CG}$, and interpreting the consequent with respect to $p$. Since imperatives have been required to be evaluated with respect to a subset of CG, it falls out immediately that counterfactual conditionals constitute impossible antecedents for imperatives.

*If your mother were stricter, brush your teeth more often!

Likewise, negation can sometimes render salient its (positive) complement proposition, enabling sequences like (42a), cf. Geurts (1999). But again, the respective discourse referent is not part of the CG anymore when it comes to evaluating the second sentence. Consequently, an imperative as in (42b) is ruled out correctly.

a. I don't have a microwave oven. I wouldn't know what to do with it.

b. I don't have a microwave oven. "Don't use it!

\section{Conclusion}

Imperatives have been shown to occur freely in all types of conditionals; in particular, the consequent of hypothetical conditionals can take the form of an imperative. Imperatives in conditionals show similar effects as overt modal verbs do. I take this to constitute additional evidence for the independently motivated hypothesis that imperatives contain modal operators. The standard construal of if-clauses constraining the restrictor of some (overt) modal operator carries over to CIs.

Imperatives have been shown to occur in epistemic conditionals, and, somewhat surprisingly, it has been argued that we can find instances of modal subordination with imperatives. These two issues have been taken together in order to argue that, as long as this is explicitly indicated, imperatives can sometimes be evaluated on a proper subset of the Common Ground. This fits well with the fact that CIs are never counterfactual.

The possibility to evaluate imperatives on a subset of CG gets us closer to the hypothetical speach act analysis (HSA) than initially expected. But the modal operator analysis (MOP) captures this not as an ad hoc-solution for CIs but in complete analogy to (i) evaluating unrestricted imperatives on the unrestricted $\mathrm{CG}$ or (ii) evaluating imperatives with respect to subsets of CG made salient in some other

\footnotetext{
${ }^{24}$ As it stands, the treatment of the ordering source is unsatisfactory since it is not part of the object (DRT-)language but happens in the model (cf. Frank 1996, Geurts 1999). Moreover, to translate the $\mathrm{MOP}_{C I}$-construal for conditionals (cf. 24), we need a slightly more complex variant of OPT.
} 
way (e.g. via modal subordination). Moreover, I have given evidence that the alternative construal of treating the imperative as the conditional operator (obtained exclusively from MOP) is needed as well (to account for overall preferences, binding contrasts, and maybe anankastic conditionals).

Technically, the analysis in terms of discourse referents for the parameters of modal operators has been sketched in a DRT language. So far, the treatment of ordering sources is not satisfactory though. Further insights into the nature of CIs may also be gained from detailed comparison with if-clauses in connection with interrogatives (cf. e.g. Isaacs 2005) and explicit performatives.

\section{References}

Aloni, Maria: 2001, Quantification under Conceptual Covers, Doctoral dissertation, University of Amsterdam.

Asher, Nicholas and Alex Lascarides: 2003, Logics of Conversation. Cambridge University Press, Cambridge.

Bhatt, Rajesh and Roumyana Pancheva: 2006, 'Conditionals', in M. Everaert and H. v. Riemsdijk (eds.), The Blackwell Companion to Syntax, 638-687. Blackwell, Oxford.

Dummett, Michael: 1964, 'Truth', in G. Pitcher (ed.), Truth, 93-111. PrenticeHall, Inc., Englewood Cliffs, New Jersey.

von Fintel, Kai and Sabine Iatridou: 2003, 'Epistemic Containment', Linguistic Inquiry 34, 173-198.

von Fintel, Kai and Sabine Iatridou: 2005, 'What to Do if You Want to Go to Harlem: Anankastic Conditionals and Related Matters'. Ms., MIT.

van Fraassen, Bas: 1973, 'Values and the Heart's Command', Journal of Philosophy 70, 5-19.

Frank, Anette: 1996, Context Dependence in Modal Constructions, Doctoral dissertation, Universität Stuttgart.

Geurts, Bart: 1999, Presuppositions and Pronouns. Elsevier, Oxford.

Groenendijk, Jeroen and Martin Stokhof: 1984, Studies on the Semantics of Questions and the Pragmatics of Answers, Doctoral dissertation, Amsterdam.

Hare, Richard: 1971, 'Wanting: Some Pitfalls', in R. Hare (ed.), Practical Inferences, 44-58. Macmillan, London.

Huitink, Janneke: 2005, 'Analyzing Anankastic Conditionals', in Proceedings of SuB 9, 140-154. NCS, Nijmegen.

Iatridou, Sabine: 1991, Topics in Conditionals, Doctoral dissertation, MIT, Cambridge, Massachusetts. Distributed by MIT Working Papers in Linguistics.

Isaacs, James: 2005, 'Imperatives and Information Growth'. Talk at Workshop on 'Imperatives', ZAS Berlin, November 25, 2005.

Kamp, Hans: 1978, 'Semantics versus Pragmatics', in F. Guenthner and S. J. Schmidt (eds.), Formal Semantics and Pragmatics for Natural Languages, 255-287. Reidel, Dordrecht. 
Kaufmann, Stefan: 2005, 'Conditional Predictions', Linguistics and Philosophy 28, 181-231.

Kratzer, Angelika: 1978, Semantik der Rede. Kontexttheorie, Modalwörter, Konditionalsätze. Scriptor, Königstein.

Kratzer, Angelika: 1991, 'Modality', in D. Stechow, Arnim von und Wunderlich (ed.), Semantik. Ein internationales Handbuch der zeitgenössischen Forschung, 639-650. de Gruyter, Berlin/New York.

Lewis, David: 1973, Counterfactuals. Blackwell, Oxford.

Lewis, David: 1975, 'Adverbs of Quantification', in E. Keenan (ed.), Formal Semantics of Natural Language, 3-15. Cambridge University Press, Cambridge.

Mastop, Rosja: 2005, What Can You Do?, Doctoral dissertation, ILLC Amsterdam.

Piwek, Paul: 2001, 'Relating Imperatives to Action', in H. Bunt and R.-J. Beun (eds.), CMC'98, LNAI 2155, 140-155. Springer Verlag, Berlin, Heidelberg.

Portner, Paul: 2005, 'The Semantics of Imperatives within a Theory of Clause Types', in Proceedings of SALT 14. CLC Publications, New York.

Ramsey, Frank P: 1929, 'Law and Causality'. Reprinted in his Foundations (1978).

Sadock, Jerrold M. and Arnold M. Zwicky: 1985, 'Speech Act Distinctions in Syntax', in T. Shopen (ed.), Language Typology and Syntactic Description, Vol. I, 155-196. Cambridge University Press, Cambridge.

Sæbø, Kjell Johan: 2002, 'Necessary Conditions in a Natural Language', in C. Fery and W. Sternefeld (eds.), Audiatur Vox Sapientiae. A Festschrift for Arnim von Stechow. Akademieverlag, Berlin.

Schulz, Kathrin: 2003, 'You May Read it Now or Later: A Case Study on the Paradox of Free Choice Permission'. MAthesis, University of Amsterdam.

Schwager, Magdalena: 2005a, 'Exhaustive Imperatives', in Proceedings of Amsterdam Colloquium, December 19-21, 2005. ILLC, Amsterdam.

Schwager, Magdalena: 2005b, Interpreting Imperatives, Doctoral dissertation, University of Frankfurt/Main.

Schwager, Magdalena: 2005c, 'Permitting Permissions', in Proceedings of the 10th ESSLLI Student Session 2005, Edinburgh.

Segerberg, Krister: 1990, 'Validity and Satisfaction in Imperative Logic', Notre Dame Journal of Formal Logic 31, 203-221.

von Stechow, Arnim: 2004, 'Schritte zur Satzsemantik'. Ms., Universtität Tübingen.

Tancredi, Chris: 2005, 'Scoping over Epistemics'. Talk delivered at Language under Uncertainty, Kyoto, January 21 - 23, 2005.

Thurmair, Maria: 1989, Modalpartikeln und ihre Kombination. Niemeyer, Tübingen.

Zarnic, Berislav: 2002, 'Dynamic Semantics, Imperative Logic and Propositional Attributes', Uppsala Prints and Preprints in Philosophy.

Zhou, Hong: 2005, 'In How Many Ways Can We Speak Conditionally'. Talk at the Semantics Colloquium, University Frankfurt, December 14, 2005.

Zimmermann, Thomas Ede: 2000, 'Free Choice Disjunctions and Epistemic Possibility’, Natural Language Semantics 8, 255-290. 